East African Medical Journal Vol. 84 No. 5 May 2007

ORTHODONTIC TREATMENT NEEDS AMONG 12-15 YEAR-OLDS IN MOSHI, TANZANIA

D.S. Rwakatema, DDS, MDS, Assistant Lecturer, Department of Dentistry, Kilimanjaro Christian Medical College, Tumaini University, P.O. Box. 3010, Moshi, Tanzania, P.M. Ng'ang'a, BDS, MSD, PhD, Associate Professor and A.M. Kemoli, BDS, DGDP RCS, MSc, Lecturer, Department of Paediatric Dentistry and Orthodontics, Faculty of Dental Sciences, University of Nairobi, P.O. Box 19676-00202, Nairobi, Kenya

Request for reprints to: Dr. D.S. Rwakatema, Department of Dentistry, Kilimanjaro Christian Medical College, Tumaini University, P.O. Box. 3010, Moshi, Tanzania

\title{
ORTHODONTIC TREATMENT NEEDS AMONG 12-15 YEAR-OLDS IN MOSHI, TANZANIA
}

\author{
D.S. RWAKATEMA, P.M. NG'ANG'A and A.M. KEMOLI
}

\begin{abstract}
Objective: To assess malocclusion and orthodontic treatment needs among 12-15-year-olds in Moshi municipality, Tanzania.

Design: A cross-sectional study.

Setting: Moshi municipality, Tanzania.

Subjects: Two hundred and eighty nine randomly selected primary school children in Moshi municipality in the year 2003.

Results: Maxillary median diastema occurred in $20.1 \%$ of the children. Crowding and spacing in the incisor segments occurred in $41.2 \%$ and $28.4 \%$ respectively with significantly more crowding in males than in females $(p=0.009)$. Anterior irregularities occurred in $46 \%$ of the sample in the maxilla and $51.6 \%$ in the mandible. These irregularities were significantly more common in the females than in males in the maxilla and mandible ( $p=0.014, p=0.037$ respectively). Reverse overjet was extremely rare $(0.3 \%)$. Anterior openbite and antero-posterior molar relation discrepancies occurred in $6.2 \%$ and $32.5 \%$ of the sample, respectively. Crowding, irregularities in the incisor segments and antero-posterior molar relation discrepancies were dominant malocclusion traits in this population. The sample mean DAI score was 24.6 points (CI $95 \% 23.86-25.36$ ). There was no statistically significant gender difference of DAI scores $(p=0.473)$. About $65 \%$ of the subjects had either no need or had slight need for treatment whereas $35.3 \%$ were found with orthodontic treatment needs ranging from elective $(21.5 \%)$, highly desirable $(6.9 \%)$ to mandatory $(6.9 \%)$. There was no significant gender difference in the categories of treatment need $(p=0.942)$. Unmet orthodontic treatment needs were present in this population with a very small proportion of subjects exhibiting handicapping malocclusion.

Conclusion: The information from this study forms part of the basis not only for further research, but also for planning orthodontic care in this community where unmet orthodontic treatment needs are present.
\end{abstract}

\section{INTRODUCTION}

Oral health services in Tanzania are currently run by a few dentists who are mostly located in the major urban areas. They are assisted by other cadres who are located in different parts of the country(2). Goals for the National Oral Health Programme of Tanzania are not clear on malocclusion affecting the children of this country. Moreover orthodontic specialists are not yet available in the country.

A few recent studies on malocclusion and orthodontic treatment need among Tanzanian children have been carried out in the capital city, Dar-es-Salaam (3). Little is known regarding 
the prevalence of malocclusion and orthodontic treatment need among children from the other parts of Tanzania (4). Indeed, a search for data on malocclusion in East Africa reveals very little information on orthodontic treatment needs among children in these countries (5-7). Effective planning of orthodontic services requires knowledge of the potential orthodontic treatment load. This planning has been defined as the number of subjects assessed to need treatment, minus those whose general condition is inadequate for treatment and those who do not wish to receive treatment (8). According to previous observations (9), orthodontic treatment need may be perceived or felt by the patient or detected by the dental professional. A previous study (6) indicated that $3-12 \%$ of Tanzanian children in Dar-es-Salaam had "absolute need" for orthodontic treatment. Objective orthodontic treatment need was found in 29\% of the 13-15 yearolds in the neighbouring Republic of Kenya (5). Since studies are few and inconclusive, there is need for additional scientific data on malocclusion and orthodontic treatment needs which can be used for planning appropriate services.

The Dental Aesthetic Index (DAI) has been frequently used for epidemiological data collection and assessment of orthodontic treatment need in most parts of the world outside Africa (10-18). It was possible to use the DAI criteria in many of these studies without modification according to the cultural diversity. However; the DAI criteria have never been used in East Africa before although they have extensively been used in other parts of Africa (19-25). The aim of this study was, therefore, to assess the frequency and distribution of malocclusion and orthodontic treatment needs in 12-15 year-olds in Moshi Municipality, Tanzania, using the DAI criteria.

\section{MATERIALS AND METHODS}

Study participants were randomly selected from all the 26 public primary schools in Moshi Municipality. In the first step, a random sample of two primary schools from each division was selected. In the second stage, each pupil aged 12-15 years in the selected schools was identified through a register and assigned a number for random selection. Based on the previous report of the prevalence of malocclusion in East Africa (26), a total number of 289 children constituted a representative sample. This sample constituted about $4 \%$ of all the public primary school children (8136 children) aged 12-15-years in the municipality. All the subjects were Tanzanians of African origin. Ethical clearance for this study was sought and obtained from Tumaini University, Kilimanjaro Christian Medical College Ethics Committee in Moshi, Tanzania. Informed consent was obtained from all the children's parents.

Data were collected in two parts; first, by self-administered questionnaire and secondly by clinical examination according to the Bjork et al. (27) criteria and the DAI criteria (28). A special clinical examination form was designed by the authors for easy recording of malocclusion traits according to both criteria where it was required. The clinical examination was carried out in a classroom under natural daylight. This was achieved by having the child sit on a chair next to a window. One investigator (DSR) carried out all the clinical examination of the subjects. A total of 24 subjects were re-examined to test the intra-examiner reliability.

Final individual DAI score points were calculated using the recommended regression equation (28). An individual final DAI score which indicated severity of malocclusion also determined the subject's orthodontic treatment need according to the cut-off points of treatment categories. Treatment categories were DAI scores of $\leqq 25$ which indicated "no or minor orthodontic treatment need" and 26-30 DAI scores which indicated "elective" orthodontic treatment need. DAI scores of 31 - 35 and $z 36$ indicated "highly desirable and mandatory" orthodontic treatment need respectively. The Kappa test (29) was used to determine intra-examiner reliability of the qualitative variables of the DAI components and related $t$-test for continuous variables of the DAI components. The Chi-square test was used to evaluate for any significant differences between males and females on the prevalence of malocclusion according to the DAI. Unrelated $t$-test was used to test the gender difference on the DAI scores. A p-value of less than 0.05 was considered significant.

\section{RESULTS}

The results for awareness and concern about malocclusion in this population were found to have been moderate (30). Overall prevalence of malocclusion according to Bjork's et al. criteria in 
this population was found to have been $97.6 \%$ (31). A kappa value of 0.95 for intra-examiner reliability of qualitative variables of DAI components was achieved. This indicated high reliability of the examined qualitative variables. There was no significant difference for continuous variables of the DAI components for the 24 re-examined subjects ( $p>0.05)$

The frequency distribution of unweighted DAI components is shown in Table 1. Maxillary median diastema occurred in $20.1 \%$ of the children. Crowding and spacing in the incisor segments occurred in $41.2 \%$ and $28.4 \%$ respectively with significantly more crowding in males than in females $(p=0.009)$. Anterior irregularities were frequent in both the maxilla (46\%) and mandible $(51.6 \%)$ with significantly more females showing irregularities than males in the maxilla and mandible $(\mathrm{p}=0.014$ and $\mathrm{p}=0.037$ respectively). Majority of the children had maxillary overjet with varying degree of expressivity. Among these 11\% had edge to edge bite and $12.1 \%$ had increased overjet ( $>4 \mathrm{~mm}$ ). Mandibular overjet was extremely rare $(0.3 \%)$. Anterior open-bite was registered in $6.2 \%$ of the sample. Antero-posterior molar relation discrepancies occurred in $32.5 \%$ of the sample.

The cumulative percentage of the sample population DAI scores is illustrated in Figure 1. The sample mean DAI score was 24.6 points (लI 95\% 23.86-25.36). The mean DAI score covered the 64 percentile of the sample DAI scores. Table 2 presents comparisons of the DAI scores according to gender. There was no significant gender difference according to the DAI scores $(\mathrm{p}=0.473)$. Table 3 presents results of orthodontic treatment need according to the DAI cut-off point of treatment categories. About 65\% of the subjects had either no need or had slight need for treatment whereas $35.3 \%$ were found with orthodontic treatment needs ranging from elective (21.5\%), highly desirable (6.9\%) to mandatory $(6.9 \%)$. There was no significant gender difference according to categories of treatment need $(\mathrm{p}=0.942)$.

Table 1

Distribution of unweighted DAI components ( $n=289$ ) and statistical gender differences (153 males, 136 females) among children in Moshi, Tanzania

\begin{tabular}{|c|c|c|c|c|c|c|c|}
\hline \multirow[t]{3}{*}{ Unweighted DAI component } & \multicolumn{4}{|c|}{ Gender } & & & \multirow{3}{*}{$\begin{array}{c}\text { P-value } \\
\text { (chi-square) }\end{array}$} \\
\hline & \multicolumn{2}{|c|}{ Male } & \multicolumn{2}{|c|}{ Female } & \multicolumn{2}{|c|}{ Total } & \\
\hline & No. & $(\%)$ & No. & $(\%)$ & No. & $(\%)$ & \\
\hline Missing visible teeth ( $\geq 1$ tooth) & 10 & $(3.5)$ & 10 & $(3.5)$ & 20 & $(6.9)$ & $0.79 v$ \\
\hline Crowding incisors $(\mathrm{mm}) 1-2$ segments & 74 & (25.6) & 45 & (15.6) & 119 & $(41.2)$ & 0.01 . \\
\hline Spacing incisors $(\mathrm{mm}) 1-2$ segments & 50 & $(17.3)$ & 32 & (11.6) & 82 & $(28.4)$ & $0.09 \sqrt{ }$ \\
\hline Maxillary median diastema ( $>1 \mathrm{~mm})$ & 33 & (11.4) & 25 & $(8.7)$ & 58 & $(20.1)$ & $0.50 \checkmark$ \\
\hline Largest anterior maxillary irregularity ( $\geq 1 \mathrm{~mm}$ ) & 60 & $(20.8)$ & 73 & $(25.3)$ & 133 & $(46.0)$ & $0.01 \bullet$ \\
\hline Largest anterior mandibular irregularity ( $\geq 1 \mathrm{~mm}$ ) & 70 & $(24.2)$ & 79 & $(27.3)$ & 149 & (51.6) & $0.02 \bullet$ \\
\hline Increased maxillary overjet $(\geq 4)$ & 16 & $(10.5)$ & 19 & $(13.1)$ & 35 & (12.1) & $0.36 \nabla$ \\
\hline Mandibular overjet $(>0 \mathrm{~mm})$ & 0 & $(0.0)$ & 1 & $(0.3)$ & 1 & $(0.3)$ & $0.47 \checkmark$ \\
\hline Anterior vertical open bite $(>0 \mathrm{~mm})$ & 8 & $(2.8)$ & 10 & $(3.5)$ & 18 & $(6.2)$ & $0.56 \mathrm{v}$ \\
\hline Antero-posterior molar relation ( $\geq 1 / 2$ cusp width) & 43 & (14.9) & 51 & (17.6) & 94 & (32.5) & $0.09 \mathrm{v}$ \\
\hline
\end{tabular}

- $=\mathrm{p}<0.05$ (males more than females); $\bullet=\mathrm{p}<0.05$ (females more than males); $\mathbf{v}=\mathrm{p}>0.05$ (no significant gender difference $p>0.05)$. 


\section{Figure 1}

Distribution of DAI scores and their cumulative percentages among children in Moshi, Tanzania

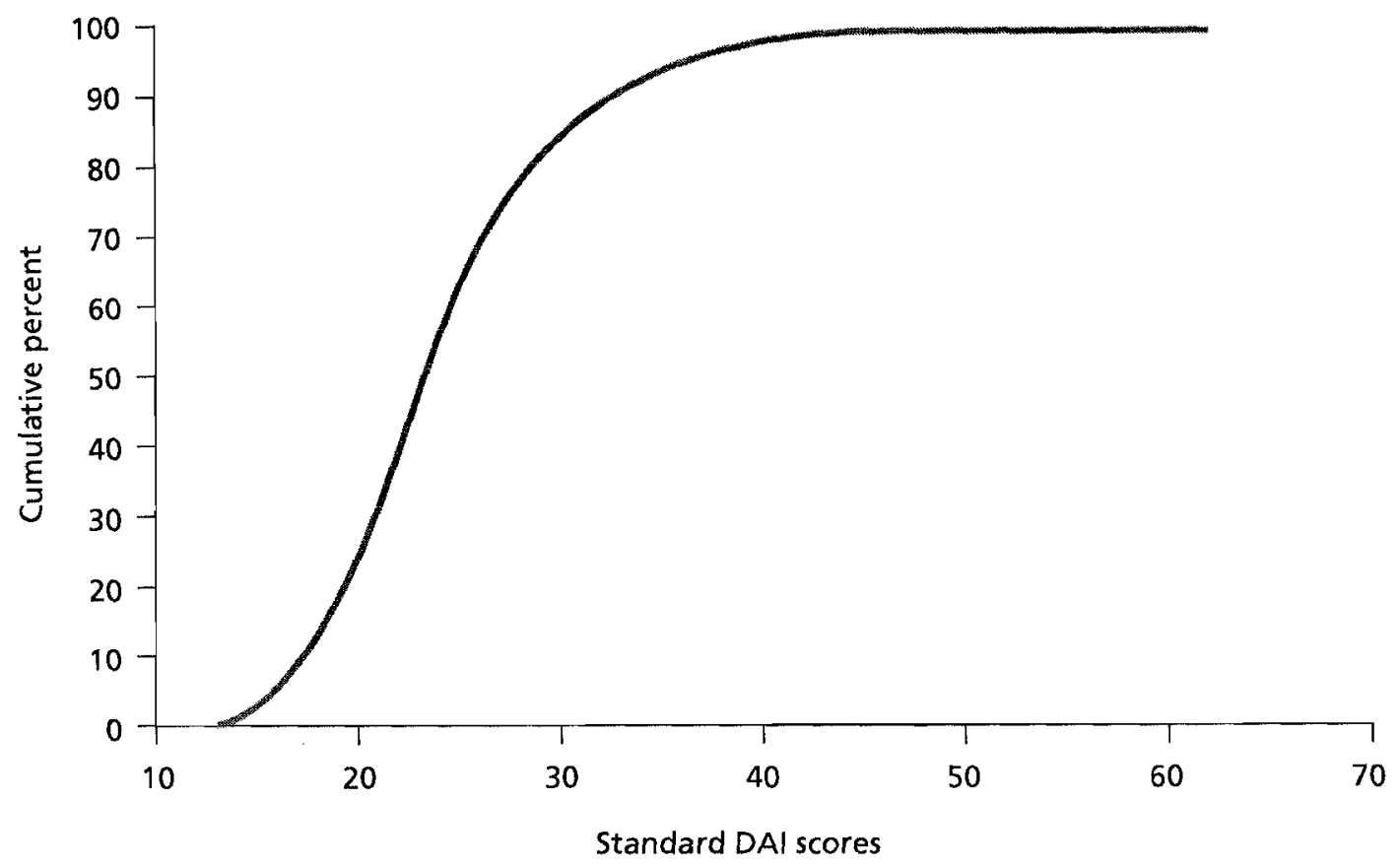

Sample mean DAI score (24.6 points (CI 95\% $23.86-25.36$ )) covered 64 percentile of the sample DAI scores and handicapping malocclusion (DAI score of $\geq 36$ ) is at the 95th percentile

Table 2

Comparisons of DAI scores according to gender among children in Moshi, Tanzania

\begin{tabular}{cccccc}
\hline & & & \multicolumn{3}{c}{ DAI Score } \\
Variable & No. & $(\%)$ & Mean & $95 \%$ CI & P-value \\
\hline Gender & & & & & \\
Male & 153 & 52.9 & 24.5 & $23.52 ; 25.48$ & \\
Female & 136 & 47.1 & 24.9 & $23.75 ; 26.05$ & 0.473 \\
\hline
\end{tabular}

There was no significant gender difference; statistics: t-test

Table 3

Orthodontic treatment needs among children in Moshi, Tanzania based on the category of treatment indications according to DAI

\begin{tabular}{|c|c|c|c|c|c|c|c|c|c|c|}
\hline \multirow{3}{*}{ Variable } & \multirow[b]{3}{*}{ No. } & \multirow[b]{3}{*}{$(\%)$} & \multicolumn{8}{|c|}{ Treatment needs } \\
\hline & & & \multicolumn{2}{|c|}{$\begin{array}{l}\text { No or slight need } \\
(\geq 25 \text { DAI Scores) }\end{array}$} & \multicolumn{2}{|c|}{$\begin{array}{c}\text { Elective } \\
\text { (26-30. DAI Scores) }\end{array}$} & \multicolumn{2}{|c|}{$\begin{array}{l}\text { Highly desirable } \\
\text { (31-35 DAI Scores) }\end{array}$} & \multicolumn{2}{|c|}{$\begin{array}{c}\text { Mandatory } \\
\text { ( } 236 \text { DAI Scores) }\end{array}$} \\
\hline & & & No. & $(\%)$ & No. & $(\%)$ & No. & $(\%)$ & No. & $(\%)$ \\
\hline \multicolumn{11}{|l|}{ Gender } \\
\hline Male & 153 & $(52.1)$ & 103 & $(67.3)$ & 29 & $(19.0)$ & 11 & $(7.2)$ & 10 & $(6.5)$ \\
\hline Female & 136 & $(47.9)$ & 84 & $(61.8)$ & 33 & $(24.3)$ & 9 & $(6.6)$ & 10 & $(7.3)$ \\
\hline Total & 289 & $(100)$ & 187 & $(64.7)$ & 62 & $(21.5)$ & 20 & $(6.9)$ & 20 & $(6.9)$ \\
\hline
\end{tabular}

There was no significant gender difference in the categories of treatment needs $(p=0.942)$; statistics: Chi-square test 


\section{DISCUSSION}

Comparison between different studies of malocclusion has usually been difficult due to lack of suitable universally accepted indices. In this regard, the Word Health Organisation (WHO) has recommended the DAI as a simple and acceptable index for use in epidemiological surveys to assess the unmet orthodontic treatment need and as a tool for screening and determining priority for orthodontic care in public-financed programmes (32). The DAI was, therefore, adapted for use in the present study. It is worthy to mention that ten DAI components on their own may have not exhausted malocclusion traits that may have been present in this sample for assessment of orthodontic treatment need. For instance, the DAI criteria takes no account of malocclusion such as buccal crossbites, central line discrepancy and increased overbite that can impinge on the palatal gingivae any of which may form a strong indication for treatment need. This is one of the reasons why the Bjork et al. (27) criteria, were also used (31) for recording such types of malocclusion traits. Although the prevalence of some malocclusion traits has been reported in the East African literature $(3,4,26)$ to the knowledge of the authors, no studies have previously employed the DAI.

Children with aplasia/impacted teeth in this study $(6.9 \%)$ were more compared to a previous report in Nigerian adolescents (3.7\%) (19) in whom the DAI criteria were used but lower than those reported in South African children (24). However; since no radiographs were used, further research is recommended to confirm this. Crowding (42.2\%) and spacing $(28.4 \%)$ in the incisor segments occurred frequently in both jaws. Similar results have previously been reported in Tanzanian (4), Kenyan (26) and South African children (24) as well as in the multiracial American population (33) of a similar age group. Diastema was commonly found (20.1\%) in this study. Although it is generally regarded as unaesthetic in the Western societies (34), general observation shows that diastema mediale is considered as a sign of beauty by many Tanzanians. A previous study(19) has reported similar findings (24.9\%) of diastemata amongst Nigerians using the DAI. However, a previous report in South African black children (24) indicated a low (17.66\%) prevalence of this trait than in our study. Anterior irregularities in the maxilla $(46 \%)$ and mandible (51.6\%) were common in this sample and were shown to have been significantly more in females than in males. Irregularities may increase with eruption stages which have been shown to occur earlier in Tanzanian females than in males (3). Concern with regard to crowding and irregularities in this population was reported by $29.1 \%$ of the respondents (30). A previous study among Tanzanian children showed severe deviations including crowding having been rated the most unaesthetic (35). About $12 \%$ of the children in the present study had increased maxillary overjet. This was much less than that reported in South African black children (29.65\%)(24) but comparable to that of a previous report in Nigerian children 14.1\%)(19). One subject was found to have had mandibular overjet $(0.3 \%)$ which agrees with a previous report regarding the rarity of this malocclusion trait in East African children (26).

Few studies on orthodontic treatment needs have been reported in Tanzania (6) and Kenya (5), using indices other than the DAI. This makes direct comparison of the present findings with the earlier observations difficult. Based on the cut-off point of $\geq 26 \mathrm{DAI}$ score, orthodontic treatment need was found in $35.3 \%$ of the examined subjects. This was high in relation to a previous report based on Nigerian children $(22.6 \%)$ (19) but lower than that of black South African children $(49.13 \%)(24)$ and those of previous reports outside Africa $(13,15,16,36)$. This demonstrates that orthodontic treatment needs in Moshi are generally low compared to many studies in other populations. A previous study (37) reported a mean DAI score of 30.1 points for Japanese and 26.5 points for white Americans which are relatively higher compared to findings in the present study and those in Nigerian children (22.3 points) (19). This may be due to racial differences. Handicapping malocclusion (DAI score of $\geq 36$ ) in the present study was at the $95^{\text {th }}$ percentile compared to the earlier minimum $86^{\text {th }}$ percentile set for the DAI as a predictor of handicapping malocclusion (38). This demonstrated that relatively few children in the present study had handicapping malocclusion needing mandatory treatment. Although DAI was chosen for use to assess objective orthodontic treatment needs in the present population, it would be worthwhile to determine norms for dentofacial appearance in Tanzania in order to ascertain the appropriateness of the index in the evaluation of orthodontic treatment need. 
In conclusion, crow ding, irregularities in the incisor segments and antero-posterior molar relation discrepancies were the dominant malocclusion traits in this population. Unmet orthodontic treatment needs were present with a very small proportion of subjects exhibiting handicapping malocclusion. The information from this study forms part of the basis not only for further research, but also for planning orthodontic care in this community where unmet orthodontic treatment needs are present.

\section{ACKNOWLEDGEMENTS}

This work is part of a Thesis submitted for the degree of Master of Dental Surgery in Paediatric Dentistry of the University of Nairobi. The authors wish to thank the World Bank through the Health Sector Development Project and the Ministry of Health, Tanzania, for funding this study. We are grateful to the authorities of Moshi Municipality, Tanzania, for allowing this study to be undertaken and the teachers and children of the primary schools visited for their cooperation. The authors appreciate the suggestions from Prof. M.L. Chindia of the Oral and Maxillofacial Surgery Department, School of Dental Sciences, University of Nairobi during the preparation of this study. The study was approved by the Ethics, Research and Standards Committee of the Kenyatta National Hospital and University of Nairobi.

\section{REFERENCES}

1. United Republic of Tanzania. Population and Housing Census. 2002.

2. Central Oral Health Unit. Policy guidelines for Oral Health Care in Tanzania. Dar es Salaam, Tanzania: Ministry of Health; 2002.

3. Mugonzibwa E.A. Need and demand for orthodontic treatment in Tanzania [PhD thesis]. Nijmegen, The Netherlands: University of Nijmegen; 2004.

4. Mugonzibwa E.A., Mumghamba E., Rugarabamu P. and Kimaro S. Occlusal and space characteristics among 12-year-old school children in Bukoba and Moshi, Tanzania. Afr. Dent. J. 1990; 4: 6-10.

5. Ng'ang'a P.M., Stenvik A., Ohito F. and Ogaard B. The need and demand for orthodontic treatment in 13-15-year olds in Nairobi, Kenya. Acta. Odontol. Scand. $1997 ; 55: 325-328$.

6. Mugonzibwa E.A., Kuijpers-Jagtman A.M., Van't Hof M.A. and Kikwilu E.N. Need for orthodontic treatment need among Tanzanian children. East Afr. Med. J. 2004; 81: 10-15.

7. Mugonzibwa E.A., Kuijpers-Jagtman A.M., Van't Hof M.A. and Kikwilu E.N. Demand for orthodontic treatment among 9-18-year-olds seeking dental care in Dar es Salaam, Tanzania. East Afr. Med J. 2004; 81: $3 \sim 9$.

8. Luffingham J.K. and Campbell M. Attitude to malocclusion amongst the parents of 10-12 year old children in Glasgow. Brit. J. Orthod. 1976; 3: 101-104.

9. Tickle M., Kay E.J. and Bearn D. Social-economic status and orthodontic treatment need. Community Dent. Oral Epidemiol. 1999; 27: 413-418.

10. Cons N.C., Jenny J., Kohout F.J., et al. Utility of dental aesthetic index in industrialised and developing countries. J. Public Health Dent. 1989; 49: 163-166.

11. Ansai T., Miyazaki H., Katoh Y., et al. Prevalence of malocclusion in high school students in Japan according to the Dental Aesthetic Index. Community Dent. Oral Epidemiol. 1993; 21: 303-305.

12. Cons N.C., Jenny J, Kohout F.J., et al. Comparing ethnic group specific DAI equations with the standard DAI. Int. Dent. J. 1994; 44: 153-158.

13. Estioko L.J., Wright F.A.C. and Morgan M.V. Orthodontic treatmentneed of secondary schoolchildren in Heidelberg, Victoria: an epidemiologic study using the Dental Aesthetic Index. Community Dent Health. 1994; 11: 147-151.

14. Takahashi F., Abe A., Isobe Y., et al. Assessment of malocclusion of Japanese junior high school pupils aged 12-13 years in Iwate prefecture according to the Dental Aesthetic Index (DAI). Asia Pac. J. Public. Health. 1995; 8: 81-84.

15. Johnson $M$. and Harkness $M$. Prevalence of malocclusion and orthodontic treatment need in 10year-old New Zealand children. Aust. Orthod. J. 2000; 16: 1-8.

16. Chi J., Johnson M. and Harkness M. Age changes in orthodontic treatment need: A longitudinal study of 10-13 year-old children, using the Dental Aesthetic Index. Aust. Orthod. J. 2000; 16: 150-156.

17. Esa R., Razak I.A. and Allister J.H. Epidemiology of malocclusion and orthodontic treatment need of 12-13 year-old Malaysian schoolchildren. Community Dent. Health. 2001; 18: 31-36.

18. Baca-Garcia A., Bravo M., Baca P., Baca A. and Junco P. Malocclusions and orthodontic treatment needs in a group of Spanish adolescents using the Dental Aesthetic Index. Int. Dent J. 2004; 54: 138-142. 
19. Otuyemi O.D., Ogunyinka A., Dosum O., et al. Malocclusion and orthodontic treatment need of secondary school students in Nigeria according to dental aesthetic index (DAI). Int. Dent. J. 1999; 49: 203-210.

20. Onyeaso C.O. Orthodontic concern of parents compared with orthodontic treatment need assessed by Dental Aesthetic Index (DAI) in Ibadan, Nigeria. Odontostomatol. Trop. 2003; 26: 13-20.

21. Onyeaso C.O. Orthodontic treatment need of mentally handicapped children in Ibadan, Nigeria, according to the dental aesthetic index. J. Dent. Child (Chic). 2003; 70: 159-163.

22. Onyeaso C.O. and Aderinokun G.A. The relationship between dental aesthetic index (DAI) and perceptions of aesthetics, function and speech amongst secondary school children in Ibadan, Nigeria. Int. J. Paediatr. Dent. 2003; 13: 336-341.

23. Onyeaso C.O. Comparison of malocclusion and orthodontic treatment needs of handicapped and normal children in Ibadan using the Dental Aesthetic Index (DAI). Niger. Postgrad. Med J. 2004; 11: 40-44.

24. Drummond R.I. Orthodontic status and treatment need of 12-year-old children in South Africa: An epidemiological study using the Dental Aesthetic Index. [Masters dissertation]. Pretoria, South Africa: University of Pretoria; 2003. Accessed on 30/5/2006 at http:/ / upetd.up.ac.za/thesis/available/etd-10 102003-165609/unrestricted/00disertation.pdf.

25. Hlonga P. and du Plessis J.B. Malocclusion among 12-year-old school children in Mankweng, Limpopo Province of South Africa. South Afr. Dent. J. 2005; 60: 455-457.

26. Ng'ang'a P.M., Ohito F., Ogaard B. and Valderhaug B. The prevalence of malocclusion in 13-15 year-old children in Nairobi, Kenya. Acta. Odontol. Scand 1996; 54: 126-130.

27. Bjork A., Krebs A.A. and Solow B. A method of epidemiological registration of malocclusion. Acta. Odont. Scand 1964; 22: 27-41.
28. WHO. Oral Health Surveys: Basic Methods. Geneva, Switzerland: World Health Organization; 1997.

29. Cohen I. A coefficient of agreement for nominal scales. Educ. Psych. Meas. 1960; 20: 37-46.

30. Rwakatema D.S., Ng' ang'a P.M. and Kemoli A.M. Awareness and concern about malocclusion among 12-15 year-old children in Moshi, Tanzania. East Afr. Med. J. 2006; 83: 92-97.

31. Rwakatema D.S., Ng'ang'a P.M. and Kemoli A.M. Prevalence of malocclusion among 12-15 year-olds in Moshi, Tanzania, using Bjork's criteria. East Afr. Med. J. 2006; 83: 372-379.

32. Jenny J. and Cons N.C. Comparing and contrasting two orthodontic indices, the Index of Orthodontic Treatment need and Dental Aesthetic Index. Amer. J. Orthod. Dentofacial Orthop. 1996; 110: 410-416.

33. Proffit W.R., Fields H.D. and Moray L.J. Prevalence of malocclusion and orthodontic treatment need in the United States: Estimates from the NHANES III survey. Int. J. Adult Orthod. Orthognath. Surg. 1998; 13: 97-106.

34. Kerosuo H., Hausen H., Laine T. and Shaw W.C. The influence of incisor malocclusion on the social attractiveness of young adults in Finland. Eur. J. Orthod. 1995; 17: 505-512.

35. Mugonzibwa E.A., Kuijpers-Jagtman A.M., Van't Hof M.A. and Kikwilu E.N. Perception of attractiveness and orthodontic treatment need among Tanzanian children. Amer. J. Orthod. Dentofacial. Orthop. 2004; 125: 426-434.

36. Abdullah M.S. and Rock. W.P. Assessment of orthodontic treatment need in 5112 Malaysian children using the IOTN and DAI indices. Comm. Dent. Hlth. 2004; 18: 242-248.

37. Katoh Y., Ansai T., Takehara T., et al. A comparison of DAI Scores and characteristics of occlusal traits in three ethnic groups of Asian origin. Int. Dent. J. 1998 48: 405-411.

38. Jenny J., Cons N.C., Kohout F.J. and Jakobsen J. Predicting handicapping malocclusion using the Dental Aesthetic Index (DAI). Int. Dent. J. 1993; 43: 128-132. 